\title{
Decrease in antibiotic use among children in the 1990s: not all antibiotics, not all children
}

\author{
Anita L. Kozyrskyj, Anita G. Carrie, Garey B. Mazowita, Lisa M. Lix, Terry P. Klassen, \\ Barbara J. Law
}

ß See related article page 139

Abstract

Background: Decreases in antibiotic use were widely reported in the 1990s. This study was undertaken to determine trends in the use of antibiotics from fiscal year (FY) 1995 (April 1995 to March 1996) to FY 2001 in a complete population of Manitoba children.

Methods: Using Manitoba's health care databases, we determined annual population-based rates of antibiotic prescription among children by antibiotic class (narrow-spectrum and broaderspectrum antibiotics), age group, physician diagnosis (e.g., otitis media or bronchitis) and neighbourhood income in urban areas (derived from the 1996 census). Antibiotic prescription rates were generated within a generalized linear model framework with general estimating equations, and differences between FY 2001 and FY 1995 were tested. Differences in antibiotic use over time were compared across antibiotic classes, age groups, diagnoses and income neighbourhoods.

Results: The overall antibiotic prescription rate decreased by almost one-third, from 1.2 prescriptions per child in FY 1995 to 0.9 prescriptions in FY 2001. Total antibiotic use declined for all respiratory tract infections; decreases were greatest for the sulfonamides (decrease to less than one-third the FY 1995 rate) and narrow-spectrum macrolides (decrease to less than half the FY 1995 rate). In contrast, the FY 2001 rate for broader-spectrum macrolides was as much as 12.5 times the FY 1995 rate. Otitis media accounted for one-quarter of the use of the latter agents. Preschool children and low-income children received the greatest number of antibiotic prescriptions. Declines in antibiotic prescriptions were of a lesser magnitude for low-income children (for whom rates in FY 2001 were four-fifths the rates in FY 1995) than for higher-income children (for whom rates in FY 2001 were about two-thirds the rates in FY 1995).

Interpretation: Overall, antibiotic use declined over the late 1990s in this population of Canadian children, but the increasing use of broader-spectrum macrolides and higher rates of antibiotic use among preschool and low-income children may have implications for antibiotic resistance.

CMAJ 2004;171(2):133-8

hildren were subject to increasing exposure to antibiotics throughout the 1980s., ${ }^{1,2}$ Concerns over increasing antibiotic resistance and inappropriate prescribing led to community-wide campaigns in the 1990 s, which were successful in decreasing antibiotic use. ${ }^{3}$

On a population basis, antibiotic use among children in the United States fell during the 1990s, ${ }^{4-6}$ but parallel decreases in antibiotic resistance were not observed. In fact, the already low susceptibility of Streptococcus pneumoniae to macrolide antibiotics has worsened, and child care centres have been identified as reservoirs of antibiotic resistance..$^{7-9}$

Decreases in antibiotic consumption have been observed in some populations in Canada ${ }^{10}$ but there are no published data on trends in antibiotic use among Canadian children. The prevalence of penicillin-resistant S. pneumoniae is on the rise among Canadian children, ${ }^{11,12}$ but we do not know which child populations are at risk for high antibiotic use. ${ }^{13,14}$ To fill these gaps in knowledge, our group evaluated antibiotic prescription patterns over the last half of the 1990s in a population of Canadian children. Trends in use across different types of antibiotics and different diagnoses, as well as in specific child populations, are described.

\section{Methods}

The study protocol was approved by the Human Research Ethics Board, University of Manitoba, and Manitoba's Health Information and Patient Confidentiality Committee. Data were obtained from 4 electronic databases maintained by the Manitoba Health Services Insurance Plan (MHSIP), which provides health insurance for all Manitobans: registration files, physician reimbursement claims, hospital discharge abstracts and records of prescriptions dispensed. The MHSIP registry contains a record for every Manitoban, and each record includes birth date, sex and geographic location. Records of physician reimbursement for medical care are submitted under a fee-for-service arrangement and contain information on patient diagnosis according to the clinical modification of the International Classification of Diseases, 9th revision (ICD-9-CM). Discharge abstracts for hospital services include information on up to 16 ICD-9-CM diagnostic codes. All dispensed prescriptions are submitted by retail pharmacies and contain information on date of dispensing, drug name and identification number, dosage form and quantity dispensed. The reliability and validity of the MHSIP's prescription and health care databases are high. ${ }^{15,16}$ Record linkages among databases were achieved through anonymized personal identifiers.

Population-based rates of antibiotic prescription, per 1000 children registered with Manitoba Health in each fiscal year (FY) (about 325000 children) during the period 1995 to 2001, were re- 
ported for all antibiotics and classes of antibiotics. Prescriptions for oral antibiotics, excluding tuberculosis drugs, were identified on the basis of the Anatomic Therapeutic Chemical classification system and generic drug names. Antibiotic classes analyzed were narrow-spectrum (NS) and broader-spectrum (BS) penicillins, NS and BS cephalosporins, NS and BS macrolides, sulfonamides and other antibiotics. Penicillin, cloxacillin, cephalexin, cefadroxil and erythromycin were defined as NS antibiotics. The BS macrolides were represented by azithromycin and clarithromycin.

Annual population-based rates of antibiotic prescription were related to age as of December in a given year (less than 1 year, 1-4 years, 5-9 years, 10-14 years and 15-19 years), physician's diagnosis and income-quintile neighbourhood. The diagnosis recorded for the physician visit that occurred within the 7-day period before an antibiotic was prescribed was assigned to the prescription. Physicians' diagnoses were grouped by the following ICD-9-CM codes: otitis media, 381-383; pharyngitis or sinusitis, 034, 461, 462, 473; asthma or bronchitis, 466, 490, 491, 493; upper respiratory tract infections, 460-479 (excluding pharyngitis and sinusitis); lower respiratory tract infections, 480-519 (excluding asthma and bronchitis); genitourinary infections, 580-629; and skin infections, 680-709. The income-quintile measure was derived from 1996 Canadian census data by aggregating household income to the enumeration area and ranking neighbourhoods from the $20 \%$ of the population residing in the lowest-income neighbourhoods to the $20 \%$ residing in the highest-income neighbourhoods. ${ }^{17,18}$

Physician visit rates per 1000 children in each fiscal year were also determined for otitis media, pharyngitis or sinusitis, asthma or bronchitis, and upper and lower respiratory tract infections. For each diagnosis, visit-based rates of antibiotic prescription (per 1000 physician visits in each fiscal year), defined as the number of antibiotic prescriptions within a 7-day period after a physician visit, were reported for all antibiotics and for the BS macrolides.

Population-based and visit-based rates of antibiotic prescription were modelled as a function of year and the other explanatory variables within a generalized linear model framework. Generalized estimating equations (GEE) were used to account for the longitudinal data and the correlation related to having the same children receiving antibiotics at multiple time points. This method of estimation produces confidence intervals (CIs) that are typically wider than those obtained from general linear models, which do not account for the dependence structure of data.$^{19}$ For the GEE analysis (normal distribution, exchangeable correlation matrix), data were organized by 50 age group and rural-urban in- come-quintile strata per year, consisting of, on average, 7200 children per stratum. A linear contrast was used to test for absolute differences in rates between FY 1995 (Apr. 1, 1995, to Mar. 31, 1996) and FY 2001. All significance tests were conducted at the $95 \%$ level of confidence.

\section{Results}

A total of 164951 (50\%) of 332059 children received at least 1 antibiotic prescription in FY 1995; this rate declined to $42 \%$ (134 717 of 322684 children) in FY 2001. The annual population-based prescription rate for all antibiotics declined by almost one-third, from 1201 prescriptions per 1000 in FY 1995 to 864 prescriptions per 1000 in FY 2001 (Table 1). Statistically significant decreases in populationbased prescription rates were observed for most antibiotic classes. Use of sulfonamides and NS macrolides decreased the most, and use of NS cephalosporins and BS macrolides increased (Table 1). For BS macrolides, the prescription rate in FY 2001 was more than 8 times the rate in FY 1995 (98 v. 12 prescriptions per 1000 children).

The total antibiotic prescription rate decreased among children of all ages, but the greatest decline was observed among infants (Table 2). Among infants, the populationbased rate for NS macrolides decreased to 25 (95\% CI 19-32) prescriptions per 1000 in FY 2001 (0.3 of the 1995 rate). Among preschool children, the population-based rate for sulfonamides decreased to 126 (95\% CI 114-138) prescriptions per 1000 in FY 2001 (0.2 of the 1995 rate). Preschool children had the highest rates of antibiotic use in both FY 1995 and FY 2001. For this group of children, the prescription rate for BS macrolides increased to 12.5 times the FY 1995 rate over the 7-year evaluation period (Table 2).

In FY 1995, population-based rates of total antibiotic use decreased successively with increasing income level among urban children, from 1327 prescriptions per 1000 in the lowest-income neighbourhood to 1157 prescriptions per 1000 in the highest-income neighbourhood. This income gradient persisted 6 years later (Table 3). Children living in the lowest-income neighbourhoods experienced

\section{Table 1: Antibiotic prescriptions per 1000 children, by year and antibiotic class (all ages combined)}

\begin{tabular}{|c|c|c|c|c|c|c|c|c|}
\hline \multirow[b]{2}{*}{ Antibiotic class } & \multicolumn{7}{|c|}{ Year; no. of prescriptions per 1000 children (and 95\% Cl) } & \multirow{2}{*}{$\begin{array}{c}\text { Ratio, } \\
\text { 2001/1995* }\end{array}$} \\
\hline & FY 1995 & FY 1996 & FY 1997 & FY 1998 & FY 1999 & FY 2000 & FY 2001 & \\
\hline NS penicillins & $109(104-114)$ & $(87-96)$ & $81(77-85)$ & $77(72-81)$ & $68(64-72)$ & $73(69-77)$ & $67(63-72)$ & 0.6 \\
\hline BS penicillins & $597(575-618)$ & $549(525-573)$ & $482(462-502)$ & $500(479-520)$ & $481(458-505)$ & $507(480-533)$ & $446(422-471)$ & 0.7 \\
\hline NS cephalosporins & $25 \quad(21-28)$ & $(22-28)$ & $25(23-28)$ & $28(26-31)$ & $33(30-36)$ & $38 \quad(35-41)$ & $36(33-40)$ & 1.4 \\
\hline BS cephalosporins & $73 \quad(65-81)$ & $(66-82)$ & $67(60-74)$ & 65 (59-71) & $61 \quad(57-66)$ & $62(57-66)$ & 57 (53-60) & 0.8 \\
\hline NS macrolides & $119(114-125)$ & $(87-98)$ & $77 \quad(72-82)$ & 79 (74-84) & $62(59-66)$ & $56(53-60)$ & $46 \quad(43-50)$ & 0.4 \\
\hline BS macrolides & $12 \quad(11-13)$ & $(17-19)$ & $25(23-26)$ & $39(38-41)$ & $57(56-59)$ & 82 (79-86) & $98 \quad(93-102)$ & 8.2 \\
\hline Sulfonamides & 222 (215-229) & 177 (171-183) & $143(137-148)$ & $131(126-136)$ & 101 (96-106) & 85 (81-90) & $67(63-70)$ & 0.3 \\
\hline Other antibiotics $†$ & $44 \quad(40-48)$ & $44 \quad(40-48)$ & 45 (40-49) & $45 \quad(40-51)$ & $45(41-50)$ & $46(41-51)$ & $47 \quad(42-52)$ & 1.1 \\
\hline Total & 1201(1172-1229) & $1070(1039-1101)$ & $944(917-971)$ & 964 (937-991) & 909 (879-939) & $949(916-982)$ & $864(832-895)$ & 0.7 \\
\hline
\end{tabular}

Note: $\mathrm{Cl}=$ confidence interval, $\mathrm{FY}=$ fiscal year (ending Mar. 31), $\mathrm{NS}=$ narrow-spectrum, $\mathrm{BS}=$ broader-spectrum.

* Linear contrast for rate difference, $p<0.001$, except for other antibiotics $(p<0.015)$

†Fluoroquinolones, tetraclyclines, clindamycin, vancomycin and metronidazole. 
the smallest decline in antibiotic prescription rates over the 7-year period (Table 3). For BS macrolides, neither the annual prescription rate nor the increase in prescription rate over time differed by neighbourhood income.

The population-based prescription rates for all antibiotics prescribed for otitis media, asthma or bronchitis, pharyngitis or sinusitis, and upper respiratory tract infections declined to 0.6 or 0.7 of the rates in FY 1995 (Table 4). The degree of decline was of a lesser magnitude for pneumonia. Changes in antibiotic prescription rates for genitourinary and skin infections were not statistically significant. Otitis media remained the most common indication for antibiotic use throughout the study period but contributed the greatest proportion $(39 \%)$ to the overall decrease in antibiotic use. In FY 2001 population-based rates of BS macrolide prescription for otitis media and upper respiratory tract infections were 10 times the FY 1995 rates. By FY 2001, otitis media accounted for one-quarter of BS macrolide use.

Physician visit rates declined for each of the respiratory infections (Table 5), but the declines were greatest for otitis media (to 0.6 of the 1995 rate) and pharyngitis or sinusitis (to 0.7 of the 1995 rate). From FY 1995 to FY 2001, statistically significant decreases in visit-based rates for antibiotics were observed for all diagnoses, but the decreases for otitis media, pharyngitis or sinusitis, and lower respiratory tract infections were small. In FY 2001, approximately $60 \%$ of physician visits for otitis media and pharyngitis or sinusitis resulted in an antibiotic prescription; for asthma or bronchitis and upper respiratory tract infections, this proportion was $35 \%$ (Table 5). Visit-based antibiotic prescription rates for BS macrolides increased for all diagnoses, but to the greatest extent for otitis media. Children seeing physicians for lower respiratory tract infections were the most likely to receive a BS macrolide prescription.

\section{Interpretation}

We have documented, for a complete population of Manitoba children, that the rate of antibiotic prescription declined by almost one-third, to 0.9 prescriptions per child, from FY 1995 to FY 2001. Eight percent fewer children received antibiotic prescriptions in FY 2001. Infants and preschool children experienced the greatest reduction in antibiotic use, and use of sulfonamides and NS macrolides declined the most among all age groups. These findings parallel decreases in antibiotic use in the general Manitoba population, and the proportionate decline was of a similar magnitude and nature to that observed among US children., ${ }^{4,510}$ No intervention campaigns were in place during the evaluation period, ${ }^{3,20}$ so decreasing antibiotic use was likely the outcome of increased physician attention to judicious prescribing of antibiotics.

Similar to trends among US children, ${ }^{4,5}$ population-based antibiotic prescription rates in Manitoba fell to the greatest extent for otitis media, pharyngitis or sinusitis, bronchitis or asthma, and upper respiratory tract infections. In parallel, physician visits for these conditions decreased, as did the

Table 2: Antibiotic prescriptions per 1000 children, by age group

\begin{tabular}{|c|c|c|c|c|c|c|}
\hline \multirow{3}{*}{$\frac{\text { Age, yr }}{<1}$} & \multicolumn{3}{|c|}{$\begin{array}{l}\text { Year; no. of prescriptions for all antibiotics } \\
\text { per } 1000 \text { children (and } 95 \% \mathrm{Cl} \text { ) }\end{array}$} & \multicolumn{3}{|c|}{$\begin{array}{l}\text { Year; no. of prescriptions for BS macrolides } \\
\text { per } 1000 \text { children (and } 95 \% \mathrm{Cl} \text { ) }\end{array}$} \\
\hline & FY 1995 & FY 2001 & $\begin{array}{l}\text { Ratio, } \\
\text { 2001/1995* }\end{array}$ & FY 1995 & FY 2001 & $\begin{array}{l}\text { Ratio, } \\
\text { 2001/1995* }\end{array}$ \\
\hline & $1330(1241-1420)$ & $803 \quad(723-883)$ & 0.6 & $12(7-16)$ & $105 \quad(96-114)$ & 8.8 \\
\hline $1-4$ & 1926 (1842-2009) & 1357 (1245-1468) & 0.7 & $15(13-17)$ & $188(169-206)$ & 12.5 \\
\hline $5-9$ & $1196(1138-1255)$ & $851 \quad$ (795-908) & 0.7 & $9 \quad(7-10)$ & 85 (77-93) & 9.4 \\
\hline $10-14$ & $743 \quad(707-778)$ & $594 \quad(556-632)$ & 0.8 & $11 \quad(9-12)$ & $55 \quad(50-61)$ & 5.0 \\
\hline$>14$ & $810 \quad(775-845)$ & $715 \quad(683-748)$ & 0.9 & $14(13-16)$ & $54 \quad(50-59)$ & 3.9 \\
\hline
\end{tabular}

* Linear contrast for rate difference, $p<0.001$.

Table 3: Antibiotic prescriptions per 1000 children, by urban income-quintile neighbourhood

\begin{tabular}{|c|c|c|c|c|c|c|}
\hline \multirow[b]{2}{*}{$\begin{array}{l}\text { Income } \\
\text { quintile }\end{array}$} & \multicolumn{3}{|c|}{$\begin{array}{l}\text { Year; no. of prescriptions for all antibiotics } \\
\text { per } 1000 \text { children (and } 95 \% \mathrm{Cl} \text { ) }\end{array}$} & \multicolumn{3}{|c|}{$\begin{array}{l}\text { Year; no. of prescriptions for BS macrolides } \\
\text { per } 1000 \text { children (and } 95 \% \mathrm{Cl} \text { ) }\end{array}$} \\
\hline & FY 1995 & FY 2001 & $\begin{array}{l}\text { Ratio, } \\
\text { 2001/1995* }\end{array}$ & FY 1995 & FY 2001 & $\begin{array}{l}\text { Ratio, } \\
\text { 2001/1995* }\end{array}$ \\
\hline 1 (lowest) & 1327 (1228-1425) & 1114 (991-1236) & 0.8 & $14(12-15)$ & $108 \quad(95-120)$ & 7.7 \\
\hline 2 & 1237 (1184-1290) & 912 (877-947) & 0.7 & $19(17-21)$ & $99 \quad(91-108)$ & 5.2 \\
\hline 3 & $1162(1092-1232)$ & 865 (822-908) & 0.7 & $13(11-15)$ & $95 \quad(89-102)$ & 7.3 \\
\hline 4 & 1179 (1089-1269) & $869(826-911)$ & 0.7 & $11(10-13)$ & $103 \quad(97-110)$ & 9.4 \\
\hline 5 (highest) & 1157 (1075-1239) & 807 (741-874) & 0.7 & $14(13-15)$ & $117(100-135)$ & 8.4 \\
\hline
\end{tabular}

*Linear contrast for rate difference, $p<0.001$. 
proportion of physician visits that resulted in an antibiotic prescription. The latter change was small for otitis media and pharyngitis. Our findings indicate that during the late 1990s there were fewer physician visits for and diagnoses of bronchitis and upper respiratory tract infections, and physicians were less likely to treat these conditions. This is a good-news story because antibiotic treatment of bronchitis and the common cold is not justified. ${ }^{21,22}$ However, as others have reported, ${ }^{4,5}$ the observed reduction in population-based rates of antibiotic use for otitis media was not primarily due to a change in physician prescribing. Acute otitis media is not treated with antibiotics in some countries, and systematic reviews have shown little benefit with antibiotic treatment. ${ }^{23}$ However, current opinion in North America is to decrease the duration of antibiotic treatment, rather than not prescribing an antibiotic at all..$^{24,25}$

In contrast to the overall trend, dispensing rates for BS macrolides increased for otitis media, pharyngitis or sinusitis, bronchitis or asthma, and upper respiratory tract infections. This trend is consistent with reported increases in use of these antibiotics in the 1990s. ${ }^{6,8,10,26}$ In FY 2001, visitbased rates for BS macrolide prescriptions were highest among children with lower respiratory tract infections, for which there is evidence from randomized controlled trials of clinical superiority of BS macrolides over other antibiotics. ${ }^{27}$ However, $6 \%$ to $8 \%$ of physician visits for otitis media, pharyngitis or sinusitis, and bronchitis or asthma that year resulted in a BS macrolide prescription. The association of asthma exacerbations with Chlamydia pneumoniae infections may warrant use of macrolides, but not BS macrolides. ${ }^{28}$ There is little justification to prescribe BS macrolides for pharyngitis ${ }^{29}$ or to select BS macrolides over other antibiotics for the treatment of acute otitis media. ${ }^{30}$ Furthermore, our findings show that BS macrolide use increased substantially among preschool children, the very population that has experienced macrolide resistance in day-care centres. ${ }^{8}$

Children in low-income neighbourhoods had the highest rates of antibiotic use over the whole evaluation period and were less likely to experience a decrease in use. Others have also reported greater use of antibiotic prescriptions by low-income children. ${ }^{13,31}$ Although respiratory tract infections are more prevalent among low-income children, many of these are viral infections, for which antibiotics are not recommended..$^{22,32} \mathrm{BS}$ macrolide rates were not higher among low-income than among higher-income children, possibly because of an inability to pay for prescriptions not meeting the treatment guidelines of Manitoba's drug insurance program. ${ }^{33}$ Some studies have reported that BS anti-

Table 4: Antibiotic prescriptions per 1000 children, by diagnosis

\begin{tabular}{|c|c|c|c|c|c|c|c|}
\hline \multirow[b]{2}{*}{ Physician diagnosis } & \multicolumn{4}{|c|}{$\begin{array}{l}\text { Year; no. of prescriptions for all antibiotics } \\
\text { per } 1000 \text { children (and } 95 \% \mathrm{Cl} \text { ) }\end{array}$} & \multicolumn{3}{|c|}{$\begin{array}{l}\text { Year; no. of prescriptions for BS macrolides } \\
\text { per } 1000 \text { children (and } 95 \% \mathrm{Cl} \text { ) }\end{array}$} \\
\hline & FY 1995 & FY 2001 & $\begin{array}{l}\text { Ratio, } \\
2001 / 1995^{*}\end{array}$ & $\begin{array}{l}\% \text { of overall } \\
\text { decrease } \dagger\end{array}$ & FY 1995 & FY 2001 & $\begin{array}{l}\text { Ratio, } \\
\text { 2001/1995* }\end{array}$ \\
\hline Otitis media & $319(250-388)$ & $189(149-230)$ & 0.6 & 39 & $2.5(1.9-3.2)$ & $25.0(19.0-31.0)$ & 10.0 \\
\hline Pharyngitis or sinusitis & $123(109-136)$ & $86 \quad(77-95)$ & 0.7 & 11 & $1.2(1.0-1.5)$ & $7.2 \quad(6.4-8.0)$ & 6.0 \\
\hline Asthma or bronchitis & $122(106-138)$ & $74 \quad(64-84)$ & 0.6 & 14 & $2.3(2.0-2.6)$ & $16.0(14.0-18.0)$ & 7.0 \\
\hline Upper RTI (i.e., cold) & $241(216-267)$ & $171(153-189)$ & 0.7 & 21 & $1.8(1.5-2.0)$ & $18.0(15.0-20.0)$ & 10.0 \\
\hline Lower RTI (pneumonia) & $40 \quad(34-46)$ & $32 \quad(27-37)$ & 0.8 & 2 & $1.2(1.0-1.3)$ & $10.0 \quad(8.0-12.0)$ & 8.3 \\
\hline Genitourinary infection & $28 \quad(24-33)$ & $27 \quad(23-31)$ & $1.0 \neq$ & NA & $0.1(0.04-0.2)$ & $0.4 \quad(0.3-0.6)$ & 3.0 \\
\hline Skin infection & $55 \quad(48-61)$ & $58 \quad(50-65)$ & $1.1 \S$ & NA & $0.3(0.2-0.3)$ & $1.7 \quad(1.3-2.0)$ & 5.7 \\
\hline
\end{tabular}

Note: $\mathrm{RTI}=$ respiratory tract infection, NS = not significant, NA = not applicable.

*Llinear contrast for rate difference, $p<0.001$, except for genitourinary infection and skin infection.

†The absolute decrease in prescriptions for each diagnosis as a percentage of the absolute decrease in total antibiotic use for all diagnoses (i.e., 337 per thousand).

$\neq p=0.8$.

$\S p=0.12$.

Table 5: Physician visit rates and visit-based rates for antibiotic prescriptions for RTIs

\begin{tabular}{|c|c|c|c|c|c|c|}
\hline \multirow[b]{2}{*}{ Diagnosis } & \multicolumn{2}{|c|}{ Population-based visit rates } & \multicolumn{2}{|c|}{ Visit-based rates for all antibiotics } & \multicolumn{2}{|c|}{ Visit-based rates for BS macrolides } \\
\hline & $\begin{array}{c}\text { Rate per } 1000 \\
\text { children, FY } 2001\end{array}$ & $\begin{array}{c}\text { Ratio, } \\
\text { 2001/1995* }\end{array}$ & $\begin{array}{l}\text { Rate per } 1000 \\
\text { physician visits, } \\
\text { FY } 2001\end{array}$ & $\begin{array}{c}\text { Ratio, } \\
\text { 2001/1995* }\end{array}$ & $\begin{array}{l}\text { Rate per } 1000 \\
\text { physician visits, } \\
\text { FY } 2001\end{array}$ & $\begin{array}{c}\text { Ratio, } \\
\text { 2001/1995* }\end{array}$ \\
\hline Otitis media & $345(272-418)$ & 0.6 & $590(576-605)$ & 0.9 & $75 \quad(70-80)$ & 10.7 \\
\hline Pharyngitis or sinusitis & $147(133-161)$ & 0.7 & $632(612-652)$ & 1.0 & $58 \quad(54-62)$ & 8.3 \\
\hline Asthma or bronchitis & $258(227-289)$ & 0.7 & $347(327-366)$ & 0.8 & $82 \quad(76-88)$ & 8.2 \\
\hline Upper RTI & $623(534-711)$ & 0.8 & $354(331-378)$ & 0.9 & $39 \quad(36-42)$ & 9.8 \\
\hline Lower RTI & $105 \quad(83-127)$ & 0.9 & $409(389-429)$ & 0.9 & $136(125-147)$ & 7.2 \\
\hline
\end{tabular}

* Linear contrast for rate difference, $p<0.05$. 
biotics are used less often in low-income children than in higher-income children. ${ }^{34}$

The immediate hazards of antibiotic use are increased side effects and costs of therapy. ${ }^{24,35}$ Recent antibiotic use also increases the likelihood that resistant strains will develop, ${ }^{9,36-38}$ and antibiotic resistance has been reported in the absence of previous antibiotic prescriptions, when community use of antibiotics is high. ${ }^{9,37}$ Resistance patterns have mirrored temporal and regional patterns of BS antibiotic use. $^{39-41}$ So, although it is not certain whether high rates of BS or any antibiotic use lead to antibiotic resistance, our data suggest that preschool and low-income children may be at greater risk for this outcome. There are also concerns over the long-term risks of asthma, especially among infants for whom BS antibiotics are prescribed..$^{42,43}$

Diagnosis information was obtained from the reimbursement claim for the preceding physician visit, which may be more accurate than physician self-reporting, ${ }^{44}$ but reimbursement claims do not record secondary diagnoses. Diagnoses of urinary tract infection have been validated, ${ }^{45,46}$ but the possibility remains that we did not correctly classify other infections. Furthermore, our analysis captured dispensed prescriptions but did not include antibiotics given as samples.

We have reported trends in dispensed antibiotic prescriptions for a complete population of Manitoba children. Antibiotic use among children has declined and antibiotics are being used less often for diagnoses for which they have limited utility. However, BS antibiotics are being prescribed more often. Low-income and preschool children remain at higher risk of exposure to antibiotics. The similarity between our FY 2001 population-based rates and those reported for Canadian children ${ }^{14}$ provides some reassurance regarding extrapolation of these findings to all Canadian children. These patterns of use may be breeding a new crisis in antibiotic resistance. Although society has responded to efforts to reduce unnecessary antibiotic use, more study into the determinants of inappropriate antibiotic prescribing is required to achieve further improvements.

This article has been peer reviewed.

From the Faculty of Pharmacy (Kozyrskyj), the Department of Community Health Sciences, Manitoba Centre for Health Policy, Faculty of Medicine (Kozyrskyj, Lix), the Department of Medical Microbiology (Law) and the Department of Pediatrics and Child Health (Kozyrskyj, Law), University of Manitoba, Winnipeg, Man.; the Faculty of Pharmacy (Carrie) and the Department of Pediatrics (Klassen), University of Alberta, Edmonton, Alta.; Community and Long Term Care, Winnipeg Regional Health Authority (Mazowita), Winnipeg, Man.; and the Child Health Program, Capital Health Authority (Klassen), Edmonton, Alta.

Competing interests: None declared.

Contributors: Anita Kozyrskyj, Garey Mazowita, Terry Klassen and Barbara Law were responsible for the conception and design of the study. All authors contributed to the analysis and interpretation of data, participated in drafting and revising the article for important content, and approved the final version for publication.

Acknowledgements: This research was conducted using the Population Health Research Data Repository at the Manitoba Centre for Health Policy, Winnipeg. We acknowledge the computer programming support of Matthew Dahl.

The study was funded by the Canadian Population Health Initiative Operating Grant Program, Canadian Institute for Health Information (CIHR). Anita Kozyrskyj is the recipient of a CIHR New Investigator Award.

\section{References}

1. McCaig LF, Hughes JM. Trends in antimicrobial drug prescribing among office-based physicians in the United States. FAMA 1995;273(3):214-9.

2. Guillemot D, Maison P, Carbon C, Balkau B, Vauzelle-Kervroedan F, Sermet $\mathrm{C}$, et al. Trends in antimicrobial drug use in the community - France, 1981-92. 7 Infect Dis 1998;177:492-7.

3. Perz JF, Craig AS, Coffey CS, Jorgensen DM, Mitchel E, Hall S, et al. Changes in antibiotic prescribing for children after a community-wide campaign. FAMA 2002;287:3103-9.

4. McCaig LF, Besser RE, Hughes JM. Trends in antimicrobial prescribing rates for children and adolescents. FAMA 2002;287:3096-102.

5. Finkelstein JA, Stille C, Nordin J, Davis R, Raebel MA, Roblin D, et al. Reduction in antibiotic use among US children, 1996-2000. Pediatrics 2003;112: $620-7$.

6. Steinman MA, Gonzales R, Linder JA, Landefeld CS. Changing use of antibiotics in community-based outpatient practice, 1991-1999. Ann Intern Med 2003; $138: 525-33$.

7. Whitney CG, Farley MM, Hadler J, Harrison LH, Lexau C, Reingold A, et al. Increasing prevalence of multidrug-resistant Streptococcus pneumoniae in the United States. N Engl 7 Med 2000;343:1917-24.

8. Hyde TB, Gay K, Stephens DS, Vugia DJ, Pass M, Johnson S, et al. Macrolide resistance among invasive Streptococcus pneumoniae isolates. $7 A M A$ $2001 ; 286 ; 1857-62$

9. Boken DJ, Chartrand SA, Goering RV, Kruger R, Harrison CJ. Colonization with penicillin-resistant Streptococcus pneumoniae in a child-care center. Pediatr Infect Dis 7 1995;14:879-84.

10. Carrie AG, Metge CJ, Zhanel GG. Antibiotic use in a Canadian province, 1995-98. Ann Pharmacother 2000;34:459-64.

11. Scheifele D, Halperin S, Pelletier L, Talbot J, Vaudry W, Jadavji T, et al. Update on penicillin resistance rates among pneumococci causing invasive infection in children - Canada, 1998 [abstract]. Paediatr Child Health 2000;5 Suppl A:37A.

12. Greenberg D, Speert DP, Mahenthiralingam E, Henry DA, Campbell ME, Scheifele DW. Emergence of penicillin-nonsusceptible Streptococcus pneumoniae invasive clones in Canada. $\mathcal{F}$ Clin Microbiol 2002;40:68-74.

13. Kozyrskyj Al. Prescription medications in Manitoba children. Are there regional differences? Can 7 Public Health 2002;93 Suppl 2:S63-9.

14. Khaled LA, Ahmad F, Brogan T, Fearnley J, Graham J, MacLeod S, et al. Prescription medicine use by one million Canadian children. Paediatr Child Health 2003;8 Suppl A:6A-56A.

15. Kozyrskyj AL, Mustard CA. Validation of an electronic, population-based prescription database. Ann Pharmacother 1998;32:1152-7.

16. Robinson JR, Young TK, Roos LL, Gelskey DE. Estimating the burden of disease. Comparing administrative data and self-reports. Med Care 1997;35(9): 932-47.

17. Wilkins R. Use of postal codes and addresses in the analysis of health data Health Rep 1993;5:157-77.

18. Mustard CA, Derksen S, Berthelot JM, Wolfson M. Assessing ecologic proxies for household income: a comparison of household and neighbourhood level income measures in the study of population health status. Health Place 1999;5:157-71.

19. Edwards LJ. Modern statistical techniques for the analysis of longitudinal data in biomedical research. Pediatr Pulmonol 2000;30:330-44.

20. Finkelstein JA, Davis RL, Dowell SF, Metlay JP, Soumerai SB, Rifas-Shiman SL, et al. Reducing antibiotic use in children: a randomized trial in 12 practices. Pediatrics 2001;108(1):1-7.

21. Rosenstein N, Phillips WR, Gerber MA, Marcy SM, Schwartz B, Dowell SF The common cold: principles of judicious use of antimicrobial agents. Pediatrics 1998;101 Suppl:181-4.

22. O'Brien KL, Dowell SF, Schwartz B, Marcy SM, Phillips WR, Gerber MA Cough illness/bronchitis: principles of judicious use of antimicrobial agents. Pediatrics 1998;101 Suppl:178-81.

23. Del Mar C, Glaziou P, Hayem M. Are antibiotics indicated as initial treatment for children with acute otitis media? A meta-analysis. BMF 1997;314: 1526-9.

24. Pichichero ME, Cohen R. Shortened course of antibiotic therapy for acute otitis media, sinusitis, and tonsilopharyngitis. Pediatr Infect Dis 7 1997;16:680-95.

25. Christakis DA, Zimmerman FJ, Wright JA, Garrison MM, Rivara FP, Davis RL. A randomized controlled trial of point-of-care evidence to improve the antibiotic prescribing practices for otitis media in children. Pediatrics 2001; 107:1-4.

26. Academic reference manual. Canadian bealth care information for pharmacy and medical students. Mississauga (ON): IMS Health; 1998.

27. Kogan R, Martinez MA, Rubilar L, Paya E, Quevedo I, Puppo H, et al. Comparative randomized trial of azithromycin versus erythromycin and amoxicillin for treatment of community-acquired pneumonia in children. Pediatr Pulmonol 2003;35:91-8.

28. Cunningham AF, Johnston SL, Julious SA, Lampe FC, Ward ME. Chronic Chlamydia pneumoniae infection and asthma exacerbations in children. Eur Respir 7 1998;11:345-9. 
29. Schaad UB, Kellerhals P, Altwegg M. The Swiss Pharyngitis Study Group. Azithromycin versus penicillin $\mathrm{V}$ for treatment of acute group A streptococcal pharyngitis. Pediatr Infect Dis 7 2002;21:304-8.

30. Kozyrskyj AL, Hildes-Ripstein GE, Longstaffe SE, Wincott JL, Sitar DS, Klassen TP, al. Treatment of acute otitis media with a shortened course of antibiotics: a meta-analysis. $7 A M A$ 1998;279(21):1736-42.

31. Petersson C, Hakansson A. High-consulting children indicate illness-prone families. A study of 38 rural and 38 urban Swedish children's health and use of medical care. Scand 7 Prim Health Care 1996;14:71-8.

32. Margolis PA, Greenberg RA, Keyes LL, LaVange LM, Chapman RS, Denny $\mathrm{FW}$, et al. Lower respiratory illness in infants and low socioeconomic status. Am 7 Public Health 1992;82(8):1119-26.

33. Reuveni H, Sheizaf B, Elhayany A, Sherf M, Limoni Y, Scharff S, et al. The effect of drug co-payment policy on the purchase of prescription drugs for children with infections in the community. Health Policy 2002;62:1-13.

34. Henricson K, Melander E, Molstad S, Ranstan J, Hanson BS, Rametsteiner $\mathrm{G}$, et al. Intra-urban variation of antibiotic utilization in children: influence of socio-economic factors. Eur 7 Clin Pharmacol 1998;54:653-7.

35. Berman S, Byrns PJ, Bondy J, Smith PJ, Lezotte D. Otitis media-related antibiotic prescribing patterns, outcomes, and expenditures in a pediatric Medicaid population. Pediatrics 1997;100(4):585-92.

36. Cohen ML. Epidemiology of drug resistance: implications for a post-antimicrobial era. Science 1992;257:1050-5.

37. Guillemot D, Carbon C, Balkau B, Geslin P, Lecoeur H, VauzelleKervroedan F, et al. Low dosage and long treatment duration of $\beta$-lactam: risk factors for carriage of penicillin-resistant Streptococcus pneumoniae. 7 AMA 1998;279:365-70.

38. Nasrin D, Collignon PJ, Roberts L, Wilson EJ, Pilotto LS, Douglas RM. Effect of beta lactam antibiotic use in children on pneumococcal resistance to penicillin: prospective cohort study. BM7 2002;324:28-30
39. Arason V, Kristinsson KG, Sigurdsson JA, Stefansdottir G, Molstad S, Gugmundsson S. Do antimicrobials increase the carriage rate of penicillin resistant pneumococci in children? Cross sectional prevalence study. BM7 1996; 313:387-91.

40. Seppala H, Kalukka T, Vuopio-Varkila J, Muotiala A, Helenius H, Lager K, et al. The effect of changes in the consumption of macrolide antibiotics on erythromycin resistance in group A streptococci in Finland. N Engl 7 Med 1997;337:441-6.

41. Manninen R, Huovinen P, Nissinen A. Increasing antimicrobial resistance in Streptococcus pneumoniae, Haemophilus influenzae and Moraxella catarrhalis in Finland. 7 Antimicrob Chemother 1997;40:387-92.

42. McKeever TM, Lewis SA, Smith C, Collins J, Heatlie H, Frischer M, et al Early exposure to infections and antibiotics and the incidence of allergic disease: a birth cohort study with the West Midlands General Practice Research Database. 7 Allergy Clin Immunol 2002;109:43-50.

43. Faroogi IS, Hopkin JM. Early childhood infection and atopic disorder. Tho$\operatorname{rax} 1998 ; 53.927-32$

44. Pichichero ME. Dynamics of antibiotic prescribing. FAMA 2002;287:3133-5.

45. Nicolle LE, Friesen D, Harding GK, Roos LL. Hospitalization for acute pyelonephritis in Manitoba, Canada, during the period from 1989 to 1992; impact of diabetes, pregnancy, and aboriginal origin. Clin Infect Dis 1996;22:1051-6.

46. Arnold SR, Allen UD, Al-Zahrani M, Tan DH, Wang EE. Antibiotic prescribing by pediatricians for respiratory tract infection in children. Clin Infect Dis 1999;29(2):312-7.

Correspondence to: Dr. Anita L. Kozyrskyj, Manitoba Centre for Health Policy, 408-727 McDermot Ave., Winnipeg MB R3E 3P5; fax 204 789-3910; kozyrsk@cc.umanitoba.ca

\section{Clinical practice Guidelines FOR THE CARE AND TREATMENT OF BREAST CANCER}

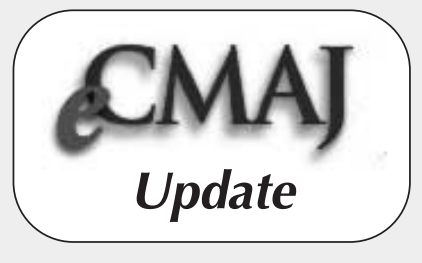

In February 1998 CMAJ and Health Canada published 10 clinical practice guidelines for the care and treatment of breast cancer, along with a lay version designed to help patients understand more about this disease and the recommended treatments. These guidelines are currently being revised and updated, and the series is being extended to cover new topics. The complete text of the new and updated guidelines is available at eCMA):

\section{www.cmaj.ca/cgi/content/full/158/3/DC1}

REVISED:

Guideline 3: Mastectomy or lumpectomy? The choice of operation for clinical stages I and II breast cancer [July 23, 2002]

Guideline 5: The management of ductal carcinoma in situ [Oct. 2, 2001]

Guideline 6: Breast radiotherapy after breastconserving surgery [Feb. 18, 2003]

Guideline 7: Adjuvant systemic therapy for women with node-negative breast cancer [Jan. 23, 2001]

Guideline 8: Adjuvant systemic therapy for women with node-positive breast cancer [Mar. 6, 2001]

Guideline 10: The management of chronic pain in patients with breast cancer [Oct. 30, 2001]
NEW:

Guideline 11: Lymphedema [Jan. 23, 2001]

Guideline 12: Chemoprevention [June 12, 2001]

Guideline 13: Sentinel node biopsy [July 24, 2001]

Guideline 14: The role of hormone replacement therapy in women with a previous diagnosis of breast cancer [Apr. 16, 2002]

Guideline 15: Treatment for women with stage III or locally advanced breast cancer [Mar. 16, 2004]

Guideline 16: Locoregional post-mastectomy radiotherapy [Apr. 13, 2004] 